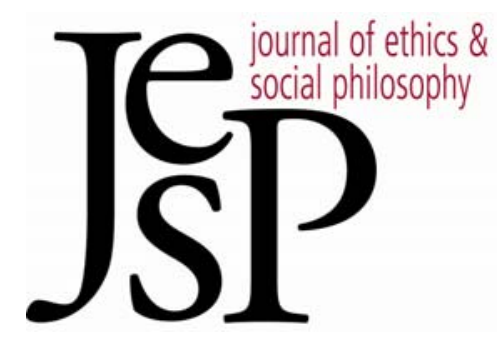

\title{
In DEFENSE OF THE WIDE-SCope INSTRUMENTAL PRINCIPLE
}

\author{
BY SIMON RIPPON
}

Journal of Ethics \& Social Philosophy

Vol. 5, No. 2 | February 2011

URL: WWW.JESP.ORG

COPYRIGHT (C SIMON RIPPON 2011 


\section{In Defense of the Wide-Scope Instrumental Principle Simon Rippon}

S UPPOSE THAT WHAT I SHALL CALL the instrumental principle is true: people have reason to take the known, necessary means to the ends they intend. ${ }^{\text {T }}$ Then it appears to follow that your intentions to pursue ends, however you arrived at them, automatically give you reasons to take certain means. This idea might seem appealing: intuitively, people who fail to take the means to their ends are in violation of the reasons for action that they have, and that is why we describe them as practically irrational. ${ }^{2}$ But it is also deeply problematic, because it makes reasons for action too easy to come by. No reason to drink the petrol in that glass? Just adopt the bizarre intention of filling your stomach with any old liquid and suddenly you will have reason to do so! I will call this the Bootstrapping Problem. ${ }^{3}$

In his much-discussed paper "The Myth of Instrumental Rationality," Joseph Raz sees the Bootstrapping Problem and concludes that the instrumental principle must be false: your actual ends and intentions do not give you reasons to take the means to fulfilling them. ${ }^{4}$ Raz's suggested alternative is, roughly speaking, the principle that you have reason to take the means to just those ends that you have undefeated reason to have. But there is an immediate difficulty with this alternative sort of proposal: it leaves unexplained the phenomenon of cleverness and its opposite. Intuitively, people who take the means to ends they have no reason to pursue (or good reason not to) seem to be rational in a certain way (a way we may call clever), while people who fail to take the means to their ends, even when they lack any good reason to have those ends, seem to display a distinctive form of irrationality (let us call them obtuse). If the instrumental principle is false and only Raz's alternative principle is true, then we seem to have no grounds for saying that clever people do any better at following the reasons they have than obtuse people do. So how are we to explain the intuition that it is more rational to be clever than to be obtuse?

We face an apparent dilemma: If we say that you have reason to take the means to the ends you actually have, the Bootstrapping Problem

\footnotetext{
1 I am especially grateful to two anonymous referees for JESP and to Selim Berker, Sharon Berry, Rachael Briggs, Iskra Fileva, Warren Goldfarb, David Gray, Christine Korsgaard, Japa Pallikkathayil, Derek Parfit, Joseph Raz, T M Scanlon, James Shaw, Jonathan Way, Ralph Wedgwood and Michael Young for their helpful comments. The initial context for discussion of these issues was made possible by Christine Korsgaard's seminar on practical reason at Harvard in 2007, funded by the Mellon Foundation.

2 I will use the phrase "the means" as shorthand for "the known, necessary means" to the end, since it is not practically irrational not to take a means one does not know about, nor to not take a sufficient means if one takes some equally good alternative sufficient means. These qualifications yield a weak but plausible version of the instrumental principle. A complete account of instrumental rationality would presumably include further principles as well.

3 Michael Bratman discusses the problem of "bootstrap rationality" in his "Intention and Means-End Reasoning," The Philosophical Review 90, no. 2 (April 1981): 252-265.

${ }^{4}$ Joseph Raz, "The Myth of Instrumental Rationality," Journal of Ethics and Social Philosophy 1 , no. 1 (2005).
} 
threatens. If we say instead that you have reason to take the means just to ends you should have, there seems to be no room left for explaining what is rational about good means-end reasoning to bad ends: the rationality of cleverness. ${ }^{5}$

I advocate a scope distinction that promises to rescue the instrumental principle from the Bootstrapping Problem. According to the proponents of the wide-scope reasons approach with whom I agree, the instrumental principle is ambiguous because the deontic ("reason") operator in it can take either wide or narrow scope with respect to an implicit conditional (I will explain this more fully below, in section 1). The instrumental principle is held to be true only on the reading in which the deontic operator takes wide scope with respect to the conditional. But this reading is not the one that entails reasons of the kind that raise the Bootstrapping Problem. ${ }^{6}$

\footnotetext{
${ }^{5}$ Raz develops his own rather sophisticated answer to this problem that unfortunately I cannot delve into here. Some other readers might think that what I have identified as the Bootstrapping Problem is not a problem at all - is it so crazy to think that we have very weak reasons to take the means to even our most bizarre and irrational ends? (cf. James Maffie, "Naturalism and the Normativity of Epistemology," Pbilosophical Studies 59, no. 3 (July 1990): 6-9.) A proponent of this view must face the difficult task of accounting for and accommodating these weak reasons, as well as the claimed difference in strength between the instrumental reasons that arise from our "bad" ends and those that arise from our "good" ends. And analogous problems to those mentioned here still arise: it is hard to explain why a merely "clever" person can easily seem just as rational, in a certain way, as a fully rational person, if it is assumed that the reasons the clever person is preoccupied by are so weak as to be obviously practically insignificant.

6 The wide-scope reasons approach was developed by John Broome and Jay Wallace. See John Broome, "Normative Requirements," Ratio 12, no. 4 (December 1999): 398419; R. J. Wallace, "Normativity, Commitment, and Instrumental Reason," Philosophers' Imprint 1, no. 3 (2001): 1-26.

Broome does not use the term "wide-scope reasons" in his 1999 paper "Normative Requirements." He claims there that what counts in favor of intending to take what you believe to be the necessary means to an end you intend is a wide-scope ought or, as he calls it, a "normative requirement." Moreover, he argues that we must avoid the mistake of "confusing normative requirements with reasons" (p. 398). It might appear from this remark that he strongly opposed the instrumental principle as I represent it, in terms of wide-scope reasons. However, this interpretation is misleading. Broome defines another normative relation in that paper that he calls a "normative recommending," which is like a normative requirement except that it makes a "slack," rather than a "strict" demand on you - that is, you may not be failing to see to something you ought to see to even if you fail to do what it counts in favor of. Normative recommendings bear the same relation of slackness to normative requirements as ordinary, narrow-scope reasons bear to ordinary narrow-scope oughts. So Broome's concept of a "normative recommending" is just what I call a "wide-scope reason." Confusion may arise because Broome uses the term "reason" exclusively to refer to narrow-scope reasons, but this restriction is arbitrary. Moreover, if the plausible thesis that, if you ought to do something, then you have a reason to do it is true, then it will follow that all normative requirements - including what Broome (1999) presents as a genuine instrumental normative requirement - entail the existence of my wide-scope reasons.

In more recent work, Broome preferred to describe what he had previously called "normative requirements" as "requirements of rationality," because he came to think it an open question whether rational requirements are normative, i.e., whether necessarily, if rationality requires of you to $F$, you have a (justifying) reason to $F$ (see, for example, “Does Rationality Give Us Reasons?,” Philosophical Issues 15, no. 1 (October 2005): 325.)
} 
Most of this paper is taken up defending the wide-scope reasons approach against an objection Raz makes to it in "The Myth of Instrumental Rationality." Raz claims there that the Bootstrapping Problem arises even on the wide-scope reason approach: on both available readings of the instrumental principle, he argues, it entails that our intending an irrational end always gives us a reason to take the means to it (I will expound his argument in sections 2-4). I will argue (in sections 5-7) that Raz's argument only looks plausible due to a natural but rather serious misunderstanding of a certain class of wide-scope reason claims - namely, claims of the form " $S$ has a reason to $p$ or to $q . "$

My argument clarifies and resolves an important debate between Raz and John Broome. Broome has raised a separate objection to Raz's argument which is not obviously successful because it relies heavily on intuitions about which reasons we have in particular cases. Broome essentially argues that a central principle that Raz is committed to, which Raz calls the "Facilitative Principle," has counterintuitive implications about which reasons we have. For example, the Facilitative Principle implies that if you have an undefeated reason to avoid killing yourself, and you could avoid feeling hungry this afternoon either by eating a sandwich or by killing yourself, then you have not only a reason to eat a sandwich, but also a reason to kill yourself.? Although Broome thinks this is obviously false, Raz claims that his intuitions differ from Broome's, and he is willing to bite the bullet in the disputed cases. ${ }^{8}$ While I am largely in agreement with Broome, I aim to build a more compelling defense of the widescope reasons approach here. By clarifying what we normally mean when we claim that " $S$ has a reason to $p$ or to $q$," my argument not only establishes that the wide-scope reasons approach is immune to the Bootstrapping Problem, but also resolves the clash of intuitions between Raz and Broome. I will show that Raz's intuitions about the particular cases, and his acceptance of the Facilitative Principle, rest on a logical mistake (section 8). I will then show that the same error also underlies a second objection to the wide-scope approach, according to which it provides too liberal an account of the instrumental reasons that we have (section 9).

Showing that these two objections to the wide-scope approach to the instrumental principle fail is significant (as I explain in section 10). The wide-scope reasons approach, if it can be defended, allows us to (i) maintain the intuition that a practically irrational agent is irrational because he fails to respond properly to the reasons that he has, (ii) readily explain why instrumentally irrational agents are irrational in the same way in one

Broome's more recent view thus leaves open the possibility that there are requirements of rationality even if there are no wide-scope reasons, such as those given by my instrumental principle. We need not adjudicate here whether Broome was correct in making that revision to his view, since even the later Broome shares my interest in defending the possibility of what I call instrumental wide-scope reasons (and thus the openness of the question of whether rational requirements are normative) against Raz's line of attack. 7 John Broome, "Have We Reason To Do As Rationality Requires? A comment on Raz," Journal of Ethics and Social Philosophy 1, no. 1 (2005).

${ }^{8}$ Joseph Raz, "Instrumental Rationality: A reprise," Journal of Ethics and Social Philosophy 1, no. 1 (April 2005): 3-4. 
important respect - whether or not they have reason to have the ends that they have - and (iii) cut off a well-known and seemingly forceful objection to the idea that rationality might be purely instrumental, according to which instrumental reasons arise only when normative force is "transmitted" from ends there is non-instrumental reason to have to the means to those ends. ${ }^{9}$

\section{The Wide-Scope Reasons Approach}

Let me begin by very briefly showing how the wide-scope reasons approach to the instrumental principle is supposed to avoid the Bootstrapping Problem. Wide-scope reasons can be explained as reasons that constrain our attitudes and actions by governing combinations of them. ${ }^{10}$ We represent this logically by containing a connective within the scope of the reason operator. Thus, a wide-scope conditional reason says that we have reason to make it the case that (if the antecedent is true, then the consequent is true). We can characterize the instrumental principle as a widescope conditional reason this way: you have reason(if you intend the end, then take the means). ${ }^{11}$

As a matter of logic, wide-scope conditional reasons do not allow for factual detachment by modus ponens, which is to say that if one has a widescope conditional reason of the form: reason(to $A$ if $P$ ), it does not follow generally from this and the fact that $\mathrm{P}$, by modus ponens, that one has reason(to $A$ ). (The latter is a reason that we can call narrow-scope, because it has no connective embedded within its scope). The use of modus ponens is blocked here because the conditional is embedded inside the scope of an operator. Compare the following invalid argument:

\footnotetext{
9 Christine Korsgaard presses this objection in her "The Normativity of Instrumental Reason," in Ethics and Practical Reason, Garrett Cullity and Berys Gaut (eds.) (Oxford: Clarendon Press, 1997), 215-54.

10 See Jay Wallace, "Normativity, Commitment, and Instrumental Reason,” 17.

11 Some philosophers have expressed semantic concerns about wide-scope normative claims like "reason(if $A$ then $B$ )." For example, it has been claimed that words like "ought" (and, by extension, terms like "reason") necessarily express relations between agents and actions (and not propositions or other entities that admit of a conditional form) (cf. Mark Schroeder, "The Scope of Instrumental Reason," Philosophical Perspectives 18, no. 1 (2004): 342-344.). I cannot fully address that objection here, but it may be worth clarifying that I understand the "reason" in constructions like reason(if $A$ then $B$ ) in this paper as shorthand for "reason to make it the case that," and whatever is inside the parentheses as shorthand for a complete proposition. So "You have reason(if $A$ then $B)$ " means that you have reason to make it the case that a certain proposition is true namely, the proposition that if $A$ then $B$.

An anonymous referee for JESP raised the different concern that when we say that there is a reason to, we can legitimately ask what fact constitutes or gives you that reason, but that this does not seem to be the case for what I am calling wide-scope reasons. On the narrow-scope view, if you have a reason to take a means $M$, we could say that your reason to take $M$ is the fact that you intend $E$, or that you have undefeated reason to intend E, or something of the sort. According to the wide-scope view, you have a reason(to $M$ if you intend $E$ ), but what fact, one might ask, is that reason provided by? My answer is straightforward: the fact that $M$ is the means to $E$ is the fact that gives you the reason(to $M$ if you intend $E$ ).
} 
Necessarily(something is on the mat if the cat is on the mat).

The cat is on the mat.

$\Rightarrow$ Necessarily(something is on the mat).

If the instrumental principle is itself expressed in terms of a wide-scope conditional reason, we cannot simply detach a narrow-scope reason to take the means based on the fact that we actually intend a certain end. So the wide-scope reading of the instrumental principle, it seems, avoids the Bootstrapping Problem.

\section{An Objection: Raz's Detachment Argument}

Raz objects that the following argument is valid. If it is valid, then even the wide-scope instrumental principle entails narrow-scope bootstrapped reasons to take the means to the ends one actually intends. (I quote the premises directly including $1 \mathrm{~B}$, Raz's interpretation of the wide-scope instrumental principle.):12

\section{The Detachment Argument}

(1B) One has reason(to do $M$ if one intends to do $E$ and $M$ is the means to $E$ ).

(2B) One intends to do $E$ and $M$ is the means to $E$.

$\Rightarrow$ One has reason to do $M$.

At first glance, it might seem that the argument above works by straightforward factual detachment by modus ponens, with $2 \mathrm{~B}$ providing the factual premise. But since, as we have seen, this move is not permissible here, we need an alternative explanation of how Raz thinks the conclusion is to be derived.

One way the Detachment Argument might be thought to work is by an application of Raz's Facilitative Principle. He explains this principle as saying that, when you have an undefeated reason to perform a certain action (a "source action"), you have reason to perform each (though not more than one) of the possible alternative "plans" that would "facilitate" its performance.13 So our "source reasons" for performing actions, according to Raz, also give us "facilitative reasons" for taking any of the

12 Raz, "The Myth of Instrumental Rationality," 12.

13 Ibid., 5-6. I have disambiguated Raz's statement of the Facilitative Principle slightly by using the phrase "each (though not more than one)" where Raz uses the words "any one (but only one)." This disambiguation opposes Broome's interpretation of Raz's principle, according to which the Facilitative Principle entails the existence of a reason to take only one plan of action - presumably the best plan that will facilitate the end (Broome, "Have We Reason To Do As Rationality Requires?," 7.) That Raz intends the former interpretation, rather than the latter, is obvious from a footnote in which he remarks: "I may have a duty to be in Oxford by noon, and buying a train ticket will facilitate getting there. But it does not follow from these facts alone that I have a duty to buy a train ticket, only that I have a [facilitative] reason to do so. The fact that there may be alternative plans facilitating fulfilment of my duty, that others may be preferable, etc., may explain this diminution in stringency." (Joseph Raz, "The Myth of Instrumental Rationality," 13; fn. 18 [my italics].) Raz means the Facilitative Principle to entail a reason to take even a suboptimal plan so long as it would facilitate the performance of the source action. 
possible plans that would lead to our taking those actions. For example, if I have undefeated reason to drink a cup of coffee, I thereby have facilitative reasons (insofar as these are possible ways for me to accomplish this) to head to the coffee shop with some cash in my pocket, to boil the kettle and put some instant in a cup, to grind some beans and start the percolator, and so on.

(Facilitative Principle) When one has an undefeated reason to perform an action, one has reason to perform each (but only one) of the possible alternative plans that would facilitate its performance.

The complex "action" that the wide-scope instrumental principle recommends is: "take $M$ if you intend E," which is logically equivalent to: "take $M \mathrm{~V}$ not intend $E$." But Raz does not think of taking $M$, or of not intending E, as "plans" that "facilitate" your performance of this "action." What we are concerned with in this case, strictly speaking, is not the relationship between a source action and facilitative reasons, but the relationship between a source action (or a state of affairs) and reasons to perform some possible actions or bring about some states of affairs which would be sufficient to constitute bringing the source action about. ${ }^{14}$ What Raz needs specifically to fill in the argument here is another principle he accepts - namely that "if one has reason to bring about a disjunctive state of affairs, then one has reason to bring about either of the disjuncts." ${ }_{15}$ Let us call this the principle of Distribution of Reasons over Disjunction (DRD):

(DRD) If one has reason to bring about a disjunctive state of affairs, then one has reason to bring about each (but only one) of the disjuncts.

DRD is not an application of the Facilitative Principle, but rather a related claim that depends on essentially the same reasoning, as Raz himself confirms: "The inference pattern I relied on in the [Detachment Argument] is fundamental to practical reasoning: People have reason to do what will bring them into conformity with reasons which apply to them. I also relied on it in arguing for ... the validity of the facilitative principle."16

What, then, is the inference pattern Raz relies on to generate both the Detachment Argument and the Facilitative Principle? It is, I believe, the following: If you have reason to bring about some state of affairs $A$, and you can bring about $A$ either by doing $B$ or by $\operatorname{doing} C$, then we may infer that you have reason to do $B$ and you have reason to do $C$ (but no reason to do both) in virtue of your reason to bring about $A$. I will call the principle underlying this inference "Liberal Transmission" for short, because it suggests that reasons are always "transmitted" from a source reason to every possible way of bringing about the state of affairs it is a reason for. It entails both DRD and the Facilitative Principle.

\footnotetext{
${ }^{14}$ Ibid., 18.

15 Raz, "Instrumental Rationality: A reprise," 2.

16 Ibid., 3.
} 
(Liberal Transmission) If you have reason to bring about $\mathrm{A}$, and you can bring about $\mathrm{A}$ either by doing $\mathrm{B}$ or by doing $\mathrm{C}$, then you have reason to do $\mathrm{B}$ and you have reason to do $\mathrm{C}$ (but no reason to do both) in virtue of your having reason to bring about $\mathrm{A}$.

We will come back later to discuss whether Liberal Transmission is in fact true. Let us for the moment put this question aside and assume for the sake of the argument that the weaker DRD is true. The wide-scope instrumental principle (1B) says that one has reason to avoid being in a situation of (intending to do $E$ and not taking $M$ ). This reason can also be understood as a reason to bring about the truth disjunctive proposition (one does not intend $E \mathbf{V}$ one takes $M$ ). By DRD, we can draw from it the implication that one has reason to take $M$. But this would be bootstrapping, so by modus tollens, according to Raz, we should conclude that the wide-scope instrumental principle is false.

There are, I believe, a number of serious difficulties with this argument. Before explaining them, I want to make sure that the reader will grant that I have represented Raz's Detachment Argument properly. Here is the core of Raz's explanation, in his own words:17

(1B) does state that one has a reason ... it is a reason to avoid being in a situation in which one would be in breach of that reason. And one would be in breach of it if one both intends $E$ and fails to do $M$. There are two ways to avoid being in that situation. One is to abandon the intention to do $E$. The other is to do $M$. So one has both a reason to do $M$ and a reason to abandon one's intention to do $E$ (though no reason to do both, because once one does one of them the reason to do the other lapses). That means that, so long as $M$ is the means to $E$ and one intends to do $E$, one has reason to do $M$. By doing $M$, when it is the means to $E$, one acts in a way that puts one on the right side of reason. By doing $M$, one conforms to the reason stated in $(1 \mathrm{~B})$. It follows that one has reason to do $M .{ }^{18}$

According to this passage, the wide-scope instrumental principle (1B) gives us reason to pursue each (but not both) of the two ways of satisfying it - taking the means or abandoning the end. Raz's claim that one "has both a reason to do $M$ and a reason to abandon one's intention to do E" represents an assertion of DRD, apparently motivated by his acceptance of Liberal Transmission (Raz does not offer a further argument for either of these principles). Now, since one obviously has no reason to abandon the end and then take the means, or vice versa, it is natural to add that "once one does one of them the reason to do the other lapses."

\footnotetext{
17 It should be noted, in fairness, that Raz's argument here may be partially founded upon a claim that Wallace makes (mistakenly, I think) in defense of a wide-scope instrumental principle. Wallace claims that "you can comply with [the instrumental principle] either by giving up the intention to [pursue the end], or by forming the intention to [take the means]" (Wallace, "Normativity, Commitment, and Instrumental Reason," 17.) While I defend the wide-scope instrumental principle against Raz's argument here, I seek to draw no conclusions about its success as a reductio of Wallace's position in that paper.

18 Raz, "The Myth of Instrumental Rationality," 12.
} 


\section{A Partial Reply, and the All Possible Ends Problem}

I want to begin to reply to Raz's argument by first noticing a problem with that last point. Even if we were to grant DRD, so that we can conclude from the instrumental principle that one has both a reason to take $M$ and to abandon one's intention to do $E$, it would be a mistake to additionally conclude that once one has done one of these, one simultaneously loses one's reason to do the other. Nothing in the argument Raz offers establishes that, once we have abandoned our intention to do $E$, we lose our reason to take $M$, or that we only gain the reason to take $M$ once we have adopted the intention to do E. (1B) states a wide-scope reason, and wide-scope reasons are not detachable by modus ponens. This means that our actual ends and intentions make no difference to the claim that (1B) makes on us.

To see this point more clearly, suppose that I have an undefeated non-instrumental reason to intend to look after my teeth. Also suppose that when I realize that looking after my teeth requires a visit to the dentist, I become irrationally frightened. I decide that I am not going to take the means to that end, and I abandon my previous intention to look after my teeth. According to Raz's argument, by abandoning the intention I will have correctly observed the reasons that I have in the light of (1B), and I will no longer have a reason to visit the dentist. But this claim must be false. Here's why: Ex bypothesi, I still have a reason to intend to look after my teeth (though I do not intend to do so). And (1B) still presents me with the following instrumental reason, since visiting the dentist is a necessary means to looking after my teeth: I have reason(if I intend to look after my teeth, then I visit the dentist). The only way of acting in accordance with both of my reasons would be to intend to look after my teeth and visit the dentist, therefore it is obvious enough that their combination entails that I have a reason to do this, and hence a reason to visit the dentist. ${ }^{19,20}$ That is, (1B) combines with my non-instrumental reason to give me a reason to visit the dentist, even though I actually lack the inten-

\footnotetext{
${ }^{19}$ It is important that the two reasons at play in this case do not conflict, if they did, they would not have combined in the way indicated here. Reasons might conflict by recommending incompatible actions or beliefs or, more generally, by being such that the justification for one undermines the justification for the other, or by being such that acting (believing) in accordance with one undermines the justification for also acting (believing) in accordance with the other. Perhaps I have some reason (e.g., testimony) to believe that $P$, and I have some other reason (e.g., I have constructed a reductio, but I might have made a mistake) to believe that If $\mathrm{P}$, a contradiction follows. These two reasons do not jointly give me reason to believe that ( $\mathrm{P}$ and a contradiction); the fact that two claims together entail a contradiction means that the reason for one belief counts against believing the other. Note that the fact that two reasons conflict need not necessarily be evident from their logical form.

20 This claim implicitly rests on the principle that a reason to perform a conjunction of actions entails reason to perform each of the conjuncts, which seems uncontroversial. Note that its truth is compatible with either response to the controversial question of whether one has any reason to bring about necessary side effects of actions one has reason to perform.
} 
tion of looking after my teeth. ${ }^{21}$ This shows that my actual intentions and ends make no difference to the reasons (1B) provides me with, at least in this sort of case. ${ }^{22}$

If we take instrumental rationality to consist in coherence between my intended ends and the means I take, then I am not, of course, instrumentally irrational in failing to visit the dentist in the case where I no longer intend to look after my teeth. But my failure to visit the dentist nevertheless indicates my failure to follow the reasons that I have. It remains the case, even after I have abandoned my intention to look after my teeth, that, if I were to follow the reasons that I have, then I would intend to look after my teeth. Further, it remains the case that if I were to follow the reasons that I have, then I would visit the dentist as a means to looking after my teeth. In this sense, I still have a reason, in the light of (1B), to visit the dentist, no matter what my current intentions.

It might be wondered what reasons (1B) would provide me with in the absence of further, non-instrumental reasons.23 On one type of Humean instrumentalist view, the only kind of reasons we have are instrumental reasons, and our ultimate ends are unanswerable to reason. Suppose an instrumentalist of this type accepts the wide-scope characterization of the instrumental principle (1B), and also accepts Raz's contention that $(1 \mathrm{~B})$ provides reasons, for a given end and means, both to take $M$ and to abandon $E$ (though no reason to do both). ${ }^{24}$ Should this instrumentalist claim, like Raz, that once she has abandoned the end of looking after her teeth, (1B) no longer provides her with a reason to go to the dentist? I can see no reason for her to think so, with one proviso. The proviso is that the example is not a case in which abandoning $E$ changes the relationship between $M$ and $E$ so that $M$ is no longer the necessary means to $E$ for the agent in question. For an example of this sort, consider a tightrope walker who intends to get to the other side by means of carefully placing one foot in front of the other. Suppose that, if this tightrope walker abandons his intention to get to the other side even momentarily, he will immediately lose his balance and fall. This tightrope walker loses his reason to carefully place one foot in front of the other if he abandons his intention to get to the other side, but only because his previous means of getting there will be ineffective as he plummets down from the wire.

There may be some intuitive pull toward claiming that abandoning the end $E$ causes one's reason to take the means $M$ to lapse, even in cases that meet the above proviso. But this pull arises from a logical scope

21 This argument also shows that, if the wide-scope instrumental principle is true and there are (as Raz assumes there are) non-instrumental reasons to intend certain ends, we need not advert to a transmission principle like Raz's Facilitative Principle to explain the existence of reasons to take the means to ends that we have decisive reasons to have. 22 Of course, my having of ends and intentions may have effects that alter the terrain of my reasons in particular cases. For example, my abandoning my intention to look after my teeth may cause them to fall out, and I may thereby lose any further reason to look after them. I assume this is not the case in the present example.

${ }^{23}$ I thank two reviewers for JESP for pressing this question.

${ }^{24}$ This contention is accepted for the sake of argument; I will challenge it later. 
confusion. What ought to be denied intuitively is that the instrumental principle (1B) provides me with a reason(to take the means and to not have the end). It is clearly true that I have no instrumental reason, in the present example, to both abandon the intention of looking after my teeth and visit the dentist. But to make this point is only to deny that I have a conjunctive reason. It is not to deny that I continue to have a pair of nonconjunctive reasons, even after I have abandoned my intention. 25 To see the distinction here, consider that while driving I may have both a reason to put my foot on the brake pedal and a reason to apply the handbrake (in each case, to prevent the car rolling down the hill). But this does not entail that I have any conjunctive reason(to put my foot on the brake and to apply the handbrake). I might, of course, have some further reason for doing both (e.g., because one of the brakes might fail), but my two separate reasons do not on their own entail that I have a single, conjunctive reason to perform both actions. Similarly, then, in the dentist example, we may feel compelled to deny that I have any instrumental reason(to visit the dentist and abandon the intention to look after my teeth). But we can do this consistently with accepting that I have instrumental reason(to visit the dentist) and instrumental reason(to abandon the intention to look after my teeth). And assuming that the case meets the above proviso - that is, assuming that abandoning my intention to look after my teeth does not affect whether visiting the dentist remains the means to looking after my teeth - we have no grounds for thinking that abandoning the intention causes my reason to visit the dentist to lapse. Raz has no grounds for concluding in general that once one abandons one's intention to pursue an end, one's reason to take the means lapses.

Raz's explicit argument against the wide-scope approach is unraveling already. He did not use the second, factual premise of the Detachment Argument to produce his conclusion, but instead simply took the wide-scope instrumental principle and invoked DRD. ${ }^{26}$ The more general point to be drawn is that the wide-scope instrumental principle does not let us derive narrow-scope reasons that depend on our actual ends, therefore our actual ends do not give us reasons on account of it, and the Bootstrapping Problem does not arise.

But perhaps my argument so far has only made the prospects for the wide-scope approach worse. If the premise that the end is actually intended plays no role in Raz's argument, does the wide-scope instrumental principle entail narrow-scope reasons to take the means to all possible ends? The suggestion that we have such reasons is counterintuitive, at best, so I will call this the All Possible Ends Problem.

25 Though I will provide different grounds for denying the claim that the instrumental principle generally provides pairs of narrow-scope reasons (see $\iint 5-6$ ).

26 Broome also points out that the factual premise plays no role in Raz's argument (Broome, "Have We Reason To Do As Rationality Requires?," 5-6.) 


\section{Raz's Argument Reformulated}

To show that the All Possible Ends Problem is not a serious threat to the wide-scope instrumental principle, I will need to show that the argument for deriving narrow-scope reasons from it still goes wrong, even if it does not attempt to invoke one's actual ends. Here is a reformulation of Raz's argument that clarifies it and drops the unnecessary reference to actual ends. If it were valid, it would show that if the wide-scope instrumental principle is true, then for any possible end one could intend, one both has reason to take the means, and reason not to intend the end:

(1C) If $M$ is the means to $E$, then one has reason(to $M$ if one intends $E$ ).

(2C) $M$ is the means to $E$.

From $(1 \mathrm{C})$ and $(2 \mathrm{C})$ :

(2.1C) One has reason(to $M$ if one intends $E$ ).

From (2.1C):

(2.2C) One has reason((not to intend $E$ ) or (to $M)$ ).

From (2.2C):

(3) One has reason to $M$.

(4) One has reason not to intend $E$.

The first step in the argument is straightforward modus ponens, so to block the conclusions, I will argue that it is one of the steps from (2.1C) to (2.2C) or from the (2.2C) to (3) and (4) that is invalid. Recall that Raz reasoned informally that a wide-scope conditional reason claim like $(2.1 \mathrm{C})$ states a constraint, that there are two ways of satisfying it, and that therefore we have reason to do each, but not both, of those things. Raz's argument here relies on two rules of inference, one that we may call the principle of Conditional Equivalence (CE), and another that looks much like the principle of Distribution of Reasons over Disjunction (DRD) that we met before:

For the step from $(2.1 \mathrm{C})$ to $(2.2 \mathrm{C})$ :

(CE) If one has a reason of the form: reason(If $A$ then $B$ ), then one has a reason of the form: reason(not $A$ or $B$ ).

For the step from (2.2C) to (3) and (4):

(DRD*) If one has a reason of the form: reason(not $A$ or $B$ ), then one has both a reason(not $A$ ) and a reason $(B)$.

Though DRD* looks very much like the earlier DRD, there is need for special care here, since Raz's argument is written in English rather than in formal logic. After the next section, I will defend DRD*, but also show how DRD* is importantly different from DRD due to a difference in meaning between English "or" in this context and the logical disjunction operator. Before I move on to that point, a brief reductio will show that at least one of the two principles CE and DRD* must be rejected. 


\section{Second Reply: A Reductio of the Reformulated Argument}

Suppose, for the sake of argument, that we all have a reason to speak the language of whichever country we are in. Suppose, moreover, that this reason is wide-scope in form. ${ }^{27}$ This is captured by the following principle:

(1L) If $L$ is the language in $C$, then one has reason(to speak $L$ if in $C$ ).

By adding to (1L) an innocent minor premise and using Raz's principles, we can now complete an argument structurally identical to the one above:

(1L) If $L$ is the language in $C$, then one has reason(to speak $L$ if in $C$ ).

(2L) French is the language in France.

(2.1L) One has reason(to speak French if in France).

(2.2L) One has reason(to not be in France or to speak French).

(3L) One has reason to speak French.

(4L) One has reason to not be in France.

But the conclusions (3L) and (4L) are a highly implausible result of such meager premises - as a matter of fact I am in England, and have no particular reason to go to France! My embracing the principle that one has a reason to speak the language (1L) surely does not, on its own, commit me to the view that, here and now, I have a narrow-scope reason to speak French (nor, indeed, to not be in France). We must therefore reject at least one of Raz's principles CE or DRD* that generate this form of argument.

\section{The Conjunctive Interpretation of "or" and Why It Matters}

The most natural understanding of wide-scope reason claims connected by the English "or" actually vindicates DRD*.28 Suppose I assert, in English, "I have reason to $A$ or to $B$." If this is to be understood as distinct from the narrow-scope reason claim: "I have reason(to $A$ ) or I have reason(to $B)$ )," then it is best understood as true if and only if my doing each of $A$ or $B$ (but not both) would count as satisfying that reason.

\footnotetext{
27 You might think that, if we do have a general reason to speak the language of the country we are in, it is a narrow-scope reason: Where $L$ is the language in $C$, if one is in $C$, then one has reason to speak $L$. But understanding the reason in question as widescope has the significant advantage of leaving open the question of whether, when applied to any particular country, the principle counts in favor of my (learning and) speaking the language, or in favor of my not being in (or not staying in) the relevant country. So a general wide-scope reason could explain, for example, both my having grounds to speak French should I visit France, and also my having, because Japanese is hard to learn, grounds to avoid being in Japan. (Of course, these grounds may not be decisive.)

28 This point is a principal difference between my response to Raz and Broome's own. Broome's reply amounts to an attempt to refute Raz's argument by denying DRD or DRD* (without distinguishing the two). My explanation of why DRD* holds for English sentences will explain why Raz might be tempted to accept the similar DRD, even though DRD is false.
} 
Think of the instructions on a ready meal: "Microwave for 4 minutes, or oven bake for 30 minutes." The instructions are best read as suggesting that I have a reason(to microwave or to bake) rather than (reason(to microwave) or reason(to bake)). I do not take a 50/50 gamble as to whether or not I act in accordance with the reasons the instructions present me with when I choose to microwave the meal! It is also not implausible to say that, when we say that I have this reason, I have reason(to microwave) and reason(to bake), and reason not to do both (or at least, no reason from this consideration to do both).

Here is another example: Suppose I am lost in a forest. I have been walking this way and that for hours and have no idea which way is which. Absent further information, I have good reason to choose a particular direction at random and then to keep walking in a straight line: this navigational principle will give me the best chance of escaping the forest. Let us simplify and suppose that I can only choose to go either due north or due south (the other directions are presently blocked). My navigational reason can also be explained as a wide-scope reason connected by the English "or": a reason(to walk north or to walk south). It is a reason to walk in each of these directions, but not more than one of them. In choosing to start walking in one particular direction, I will be taking a gamble about whether it is the shortest way out of the forest, and therefore - arguably - about whether I am walking in the direction I have most "objective" reason to take. But I will not be gambling about whether I am obeying the reason that my navigational principle provides me with; whichever direction I choose to walk in, that principle gives me a good reason to do so, and not to walk in various different directions.

These examples indicate that, on the usual interpretation, wide-scope reason claims connected by the English "or" do indeed imply narrowscope reasons to perform the actions on either side of the connective, so DRD* is vindicated. But the acceptance of DRD* now gives us clear grounds for rejecting CE. Combining (1L) with the minor proposition (2L), we straightforwardly derived: (2.1L) One has reason(to speak French if in France). Intuitively, everything we have assumed so far is consistent with the assumption that, here and now in England, I have no reason whatsoever to speak French. But we have seen that the natural interpretation of: (2.2L) One has reason(to not be in France or to speak French) entails that I have a reason to speak French, and therefore contradicts the last assumption. Therefore, (2.2L) cannot be entailed by (2.1L), and we must reject CE.

To deny $\mathrm{CE}$ is to say that a wide-scope reason connected by the English "if ... then" does not entail its apparent equivalent connected by the English "or." That I have wide-scope reason to speak French if in France does not entail that I have a reason that can be properly represented in English as a "reason not to be in France or to speak French." We know this because, on the narrow-scope reading, this last claim entails that I have at least one of those reasons and, on the wide-scope reading, as we have seen, it entails that I have both!

These results may appear to entail a denial of the intersubstitutivity of logical equivalents within the scope of the reason operator, and this 
would be puzzling. A simpler explanation is that one of the English connectives involved is not translatable to its most obvious logical counterpart, so that the two English sentences in question are not in fact logically equivalent. In fact, a wide-scope "reason to $A$ or to $B$ " as stated in English is not naturally interpreted as equivalent to a disjunctive reason(to $A \mathbf{v}$ to $B$ ) - where the connective is " $\mathbf{v}$ " ( $\mathrm{read}$ as $v e)$, the logical disjunction operator. It is generally to be interpreted, rather, as equivalent to one of two conjunctions of reason claims: either to a reason(to $A$ ) \& a reason(to $B) \&$ [from the contextually relevant consideration] no reason(to $A \&$ to $B$ ) (e.g., as when one has reason to staple a sheaf of pages or use a paper clip, and no reason to do both), or to a reason(to $A) \&$ a reason(to $B$ ) \& a reason not (to $A \&$ to $B$ ) (e.g., when one has reason to walk north or to walk south, and not alternately in each direction, when lost in the forest). This interpretation makes it obvious why DRD* is a useful rule of inference for wide-scope reason claims over the English "or": since these claims have the logical form of a conjunction it is not surprising that, when they are true, their conjuncts are also true!

There is, of course, no reason to think that a conditional reason such as reason(to $B$ if not $A$ ) should entail a conjunction of reason claims like those just outlined, and this gives us clear grounds for rejecting CE: A wide-scope reason(to $B$ if not $A$ ) is not equivalent to a wide-scope "reason to $A$ or to $\mathrm{B}$," where the latter is to be understood as suggested above. It is, rather, equivalent to a disjunctive reason(to $A \mathbf{V}$ to $B$ ), a reason which is hard to state in a natural English sentence except as a conditional, or else as the negation of a conjunction: "reason not (to not $A$ and to not B)."

My thesis about "or" may at first seem radical, but the idea that the English "or" in certain contexts should be interpreted as a logical conjunction is nothing new: philosophers and linguists have long addressed it under the heading of "the problem of free choice permission." This name comes from certain sentences granting permission, such as, "You can have milk or lemon in your tea," which implies that you can have milk and you can have lemon but you cannot have both.29 The "problem" discussed is how to best explain the special interpretation of "or" needed in such contexts: as a feature of semantic meaning, as a pragmatic implicature, or as something else. That concern is orthogonal to the present discussion: what is important here is just that sentences of this sort are generally understood as having such an import (whether semantic or pragmatic) - thus making us licensed, and liable, to draw certain inferences from them that we should not draw from genuinely disjunctive claims. As far as I know, nobody has previously noticed the significance of conjunctive uses of "or" in the deontic contexts in which I detect them here.

Making use of the conjunctive interpretation of the English "or" allows us to continue to understand the reason operator as functioning

29 Ralph Wedgwood helpfully raised this example in his commentary on an earlier version of this paper. 
logically in ordinary ways. If we substitute the logical " $\mathrm{v}$ " for the English "or" in CE and DRD* we can then accept the principle:

$\left(\mathrm{CE}^{*}\right)$ If one has a reason of the form reason(If $A$ then $B$ ), then one has a reason of the form reason(not $A \vee B$ ).

CE* is either a simple instance of substitution of logical equivalents, or an entailment between an English conditional that is stronger than the material conditional and the disjunctive logical equivalent of the material conditional. It is, therefore, difficult to deny from a logical point of view.

Let us return to our near-relative of DRD*, the principle of Distribution of Reasons over Disjunction:

(DRD) If one has a reason of the form: reason(not $A \vee B$ ), then one has both a reason(not $A$ ) and a reason(B).

It is the principle we came across first when Raz took himself to make use of it in the Detachment Argument. I will now argue that we should deny it. There is an alethic modal analogy we can use to show that denying DRD is not prima facie implausible. From: necessarily $(p \mathbf{V}$ not $p$ ), it does not follow that the disjunction of narrow-scope modals (necessarily $(p) \vee$ necessarily $(\operatorname{not} p))$ is true; similarly from: $\operatorname{reason}(A \vee B)$, it need not follow that the disjunction of narrow-scope reasons (reason $(A) \mathbf{V}$ rea$\operatorname{son}(B))$ is true, let alone that the conjunction of these narrow-scope reasons is true. ${ }^{30}$

More importantly, the denial of DRD is supported by the threat of a reductio similar to the one I already provided: I could surely be committed to the claim $(2.1 \mathrm{~L})$ that one has reason to speak the local language (in general) without being committed to thinking, here and now, that I have any narrow-scope reasons at all to speak French, or to not be in France. But we have accepted $\mathrm{CE}^{*}$, and if $\mathrm{CE}^{*}$ and DRD were both true, such narrow-scope reasons would be entailed by the wide-scope claim. This gives us sufficient grounds for denying DRD. ${ }^{31}$ Wide-scope reasons like (2.1L) do not on their own provide us with narrow-scope reasons, so DRD must be false.

\footnotetext{
30 The analogy with the modal necessity operator should not be taken too far: in contrast with it, agglomeration is not permissible, i.e., (reason(to $A$ ) and reason(to $B$ )) does not entail reason(to $A$ and to $B$ ). The reason operator is analogous to the modal possibility operator in this respect.

31 Astute readers may notice that, according to my foregoing arguments, the claim $(2.1 \mathrm{~L})$ may entail that I have a reason, here and now, to speak French: it will do so if I have a reason to be in France that does not conflict with the reason given by $(2.1 \mathrm{~L})$. This may seem implausible at first, but it will not seem so implausible if we realize that my combined reason is just a reason, here and now, to be in France and speak. French. It will not do anything for my acting in accordance with $(2.1 \mathrm{~L})$ if I speak French here and now in England. Doing so will be superfluous to making true the disjunction (speak French not be in France), since that disjunction is already true, and it will additionally falsify another disjunction that (2.1L) equally gives me a reason to satisfy: (speak English not be in England).
} 


\section{Understanding Wide-Scope Conditional Reasons}

We are finally in a position to finish up our reply to Raz in the following way: to say that one has a wide-scope conditional reason is to say that one has a reason not to do both of the things that make the antecedent true and the consequent false. But this is not to say that one has reasons to do each (but not both) of making the consequent true and falsifying the antecedent, nor indeed to say that one has either of those narrow-scope reasons. It is only to say that one has a wide-scope disjunctive reason(to make the antecedent false $\mathbf{V}$ to make the consequent true). This reason need not entail the existence of any narrow-scope reasons. The cause of mistakenly thinking otherwise is that the natural way to try to express the disjunctive reason claim in English is to say that "one has reason to make the antecedent false or the consequent true." But to make this claim, on the natural wide-scope interpretation of it, is to change the subject by making a claim about a conjunction of narrow-scope reasons. It is to mistakenly think of the wide-scope disjunctive reason as in every case giving us "options," when in fact it does no such thing.

In showing that CE and DRD must be rejected, I have shown that the argument for deriving simple narrow-scope reasons to take the means to any end from the wide-scope instrumental principle fails (or at least, that it fails absent an additional normative premise, such as a premise that there is reason to intend the end). This point therefore successfully defends the wide-scope instrumental principle against both the All Possible Ends Problem and the Bootstrapping Problem.

\section{Generalizing the Lesson: Against Liberal Transmission and the Facilitative Principle}

I suggested earlier that Raz might rest both DRD and the Facilitative Principle on a more general principle, the Liberal Transmission principle, that says: If you have reason to bring about $A$, and you can bring about $A$ either by doing $B$ or by doing $C$, then you have reason to do $B$ and you have reason to do $C$ (but no reason to do both). In denying DRD, I am committed to denying Liberal Transmission as well; I am claiming that you can have a reason to bring about the truth of a disjunction without having any particular reasons to bring about the truth of each of the disjuncts, even though either action would be sufficient to bring about the truth of the disjunction. If the Facilitative Principle is derived from Liberal Transmission, the argument that undermines DRD serves to undermine the grounds for the Facilitative Principle as well. But in any case, all three principles can be seen as motivated by the same informal argument that trades on a confusion about the logical form of wide-scope reason sentences connected by the English "or":

(1) You have reason to do $A$.

(2) You can do $A$ by doing $B$ or by doing $C$.

(3) $\Rightarrow$ You have reason(to do $B$ or to do $C$ ).

(4) $\Rightarrow$ You have reason to do each of $B$ and $C$, but not both.

(5) $\Rightarrow$ You have reason to do $B \&$ You have reason to do $C$. 
It is the step from (3) to (4) that invokes the special conjunctive interpretation of the English "or." 32 If we understand that "or" in step (3) as a true disjunction, there is no way to derive step (4) from it. If, alternatively, we understand it in the way I have described, as a conjunction, there is no way to derive it from premises (1) and (2).

That there is no way to derive step (4) from the disjunctive interpretation of (3) follows from the more general truth that you can have reason to do something even if you do not have reason to do it in each and every one of the possible ways in which it can be done. I have already suggested that one's reason to take the means to one's ends should be understood in this spirit, but it is also supported by our intuitions about many other ordinary claims about the reasons that we have. For example, I may have reason to crack a joke at dinner, without having any reason to crack a racist, sexist and otherwise generally offensive one. I may have a reason to go to the party and have a drink, without having any reason to go to the party and have a drink of petrol.33 In other cases, some ways of doing what we have reason to do would quite explicitly defeat the purpose of doing it: I may have reason to get some money in order to buy a lottery ticket, but I have no reason do it by selling my existing lottery ticket.

Reflection on such examples indicates that it is not the case that having reason to do something entails having reason to do it in each of the possible ways there is of doing it. Nor is it the case that having undefeated reason to do something (as Raz puts it in his statement of the Facilitative Principle) entails that you have reason to perform each possible plan that would facilitate its performance. My thesis about how the conjunctive "or" in a wide-scope reason claim may be confused with a logical disjunction provides a debunking explanation for why philosophers have been tempted to think otherwise. The present argument thus undermines Raz's argument for the Facilitative Principle as well as his objection to the wide-scope reasons approach.

The argument I have laid out also makes a more radical claim about the relationship between wide-scope and narrow-scope reasons. It is not merely the case that you can have a reason to do something without having a reason to do it in each possible particular way in which it could be done; it is also the case that you can have a reason to do something without having a reason to do it in any possible particular way in which it could be done. That is to say, you could still have a reason(to $A \mathbf{v}$ to $B$ )

\footnotetext{
32 The conjunctive "or" may be present in premise (2) as well, but its presence or absence there makes no difference to the following argument.

${ }^{33}$ It may be possible to bite the bullet about these examples and say that one does have some reason to do these things, though the reasons to do them are small and massively outweighed. Mark Schroeder offers an interesting pragmatic account of why it may sound odd to assert the existence of reasons that are small and massively outweighed in his Slaves of the Passions (Oxford: Oxford University Press, 2007). However, it would seem at least prima facie preferable to take our intuitions about the non-existence of the relevant reasons at face value.
} 
even if you had no reason(to $A$ ) and no reason(to $B$ ). This is because your wide-scope reason to make it the case that a disjunction is true need not arise from, or be accompanied by, any particular reasons for making either of the disjuncts true; it would still be true even if the only reason you have is some reason not to both (not $A \&$ not $B$ ).

My claim that you can have a wide-scope disjunctive reason while lacking any narrow-scope reasons is not, of course, to be equated with the paradoxical claim that a disjunction could be true without either of its disjuncts being true. The disjunction is embedded here within the scope of the reason operator, so there should be no air of paradox about it. It is analogous to the familiar claim about modal necessity: necessarily $(p \mathbf{V}$ not $p)$ may be true even though neither necessarily $(p)$ nor necessarily (not $p$ ) is true. But I want to draw a yet closer analogy that wide-scope reasons bear to wide-scope requirements. In the case of requirements, it is quite clear that one can be subject to a wide-scope requirement without being subject to any narrow-scope requirements. For this reason, a version of Raz's detachment argument that was applied to a wide-scope requirement would have been implausible on its face. Suppose, for example, that I am subject to no reasons and requirements but a single wide-scope disjunctive requirement that I recognize: I am required(to $A \mathbf{v}$ to $B$ ). Then my doing either $A$ or $B$ may be motivated by the thought that I am required to do it. Suppose I do $A$. Then it would be misleading to explain my motivation by saying that I was required to do precisely what I did; I was rather required(to $A \mathbf{V}$ to $B$ ). This can be shown by the fact that, if I had recognized myself to be under two requirements - the one mentioned already and a second, narrow-scope requirement to $A$ - and supposing that it were only possible for me to perform one of $A$ or $B$, and I knew this, then I would not have been able to $B$ and rationally be motivated by the thought that I was required to do it.

The same goes for wide-scope reasons. Suppose, for example, that I am subject to no reasons and requirements but a single wide-scope disjunctive reason that I recognize: I have reason(to $A \mathrm{v}$ to $B$ ). Then my doing either $A$ or $B$ may be motivated by the thought that $\mathrm{I}$ have reason to do it. Suppose I do $A$. Then it would be misleading to explain my motivation by saying that I had reason to do precisely what I did; I rather had reason(to $A \mathbf{v}$ to $B$ ). It follows that wide-scope disjunctive reasons or requirements need not entail the existence of narrow-scope reasons or requirements, and may be acted upon rationally even so.

The instrumental principle should, I believe, be understood in the way I have outlined here. We should not think that the existence of a reason to take the means to your ends depends on or entails either your having any reasons for taking particular means, or your having any reasons for not having particular ends. This is because it is plausible that your reason to take the means to your ends is ultimately just a reason of instrumental rationality: a wide-scope reason governing combinations of attitudes, or actions and attitudes, and not a reason of any other kind. 


\section{The Wide-Scope Instrumental Principle and "Process" Reasons}

The account of wide-scope reasons presented here enables us to respond to an additional objection to the wide-scope approach that has been developed in detail by Niko Koldony. ${ }^{34}$ Koldony speaks in terms of (rational) "requirements," but I will translate his objection into the language of "reasons" in order to address a potential argument that might be made against the principle defended here. Kolodny argues that the requirements of rationality are not "state" but "process" requirements, where state requirements require you to be a certain way, whereas process requirements require you to do something over a period of time. Process requirements, Kolodny says, can be normative in the sense that they "can function as advice or guide your deliberation," whereas state requirements "cannot be normative in this sense, since they do not tell you to do anything. At most, state requirements might be evaluative requirements that is, necessary conditions for qualifying for a certain kind of appraisal." ${ }_{35}$ Translated into the language of reasons, we might say that state reasons are reasons to be a certain way, whereas process reasons are reasons to do things over time. If he wished to advocate the parallel distinction among reasons, Kolodny might say that, whereas process reasons can function as advice or guide your deliberation by counting in favor of a certain course of action, state reasons can only count in favor of making a certain kind of appraisal.

Kolodny's analysis leaves us with two competing readings of my wide-scope instrumental principle, depending on which function it is intended to play. In terms of state reasons, it would then be expressed as:

(WS) You have reason to not be in the following state: that you intend $E$ but will not take $M$.

In terms of process reasons, it would be expressed as:

(WP) You have reason to avoid or exit, in whatever way you like, the following state: that you intend $E$ but will not take $M .{ }^{36}$

The objection to my wide-scope instrumental principle then proceeds as follows: If we are interested in describing the instrumental reasons that we have to do things, then neither of these interpretation of the widescope instrumental can be satisfactory. That task should interest us in process reasons, rather than state reasons, and therefore in WP in particular. A man who, upon recognizing a necessary means to his ends, consistently abandons his ends, satisfies WP - but he is not a good example of

34 See Niko Kolodny, "Why Be Rational?," Mind 114, no. 455 (July 1, 2005): 509-563; Niko Kolodny, "State or Process Requirements?," Mind 116, no. 462 (April 2007): 371385. See also the reply by John Broome, "Wide or Narrow Scope?," Mind 116, no. 462 (April 1, 2007): 359-370.

35 Kolodny, "State or Process Requirements?," 371-72.

36 The alternative readings here closely parallel those of a rational requirement given by Kolodny in "State or Process Requirements?," 372. 
an instrumentally rational agent. So WP is too liberal an interpretation of the instrumental process reasons that we have. ${ }^{37}$

This argument threatens to force us to abandon the wide-scope reading of the instrumental principle when it is intended as a guide to action. But the discussion of this paper shows why WP need not be accepted as the proper interpretation of the wide-scope instrumental principle even in terms of process reasons. As I argued above, you can have reason to make a disjunction true without having reason to make each of its disjuncts true. Therefore, if we wanted to represent wide-scope instrumental principle explicitly as a process reason, part of WP should be omitted, and it should rather be presented as:

(WP2) You have reason to avoid or exit the following state: that you intend $E$ but will not take $M$.

The crucial point here is that WP2 does not imply that you have any reason to not intend $E$, nor any reason to take $M$. It says you have a reason simply to avoid or exit a certain state. While it is, of course, necessary that you either not intend $E$ or take $M$ in order that you avoid or exit the state, and you do have reason to avoid or exit the state, according to WP2, it does not follow that you have reason to do either of these things in particular. This is just what my denial of DRD, of Raz's Facilitative Principle, and of Liberal Transmission implies. You can have undefeated reason to do something even if you do not have reason to do it in every possible way in which it can be done.

Using WP2 rather than WP as our interpretation of the wide-scope instrumental principle allows us to respond to the example of a man who consistently abandons his intentions upon recognizing the necessary means to them. Such a man does indeed, in every particular case, avoid or exit the state of intending $E$ but not taking $M$. But we can glean no information from WP2 alone about whether, in every such case, he avoids or exits the state in a particular way in which he has a reason to avoid or exit it. Given certain widely shared background assumptions about what we have reason to do, people have undefeated reason to intend certain ends. As I argued earlier, such reasons would combine with our widescope instrumental reasons (here expressed as WP2) to provide us with reason to take the means to those ends. And this explains the intuition that there is something imperfectly rational about someone who consistently abandons his intentions on recognizing the necessary means to them.

It might be objected that there is something defective about WP2 understood as a statement of process reasons, because when considered on its own it does not tell us which particular actions we have a reason to perform. But it is difficult to see why we should accept any such constraint on what counts as a legitimate statement of a process reason. In general, when we describe our reasons, we properly ignore various ways in which we have no reason to act that the specified reason may seem

${ }^{37}$ I thank a reviewer for JESP for pressing this objection. 
superficially to count in favor of. If you tell me I have a reason to go to London, it is no objection to point out that I have no reason to crawl there on my hands and knees.

\section{The Promise of the Wide-Scope Approach}

The wide-scope reasons approach is, I believe, worth defending. It offers a simple and unitary explanation of why instrumental irrationality is something that can be criticized whether or not the agent has reason to have, or not have, the end he does. Someone who intends an end but does not take the means to it does not act in accordance with the widescope reasons that he has. He fails to make it the case that, if he intends the end, he takes the means. "Instrumental reasons" are best conceived of as wide-scope reasons, rather than narrow-scope reasons to take the means to our ends, or to the ends that we should have. That way, we can say that all instrumentally irrational agents act against their instrumental reasons.

Since we did not need to derive any narrow-scope reasons either from the agent's actual ends or from the ends he ought to have in order to know that he has violated his reasons, this account of instrumental rationality does not require "transmission" of normative force from ends to means. It is conceivable, on this account, that agents in fact have widescope instrumental reasons and no other reasons whatsoever. It is conceivable, therefore, that rationality is purely instrumental.

An important question remains: why think that we actually have the wide-scope reasons expressed by the instrumental principle? I have not attempted to answer this question here. But I have cleared away a problem that made answering it seem impossible from the get-go: I have shown why the instrumental principle, read as a schema for wide-scope instrumental reasons, is a credible account of at least some of the reasons that we take ourselves to have.

Simon Rippon

Oxford Uehiro Centre for Practical Ethics

and Somerville College, Oxford

simon.rippon@philosophy.ox.ac.uk 